\title{
Links between Central West Western Australian Rainfall Variability and Large-Scale Climate Drivers
}

Fierro, Alexandre O; Leslie, Lance M . Journal of Climate ; Boston 26.7 (Apr 1, 2013): 2222-2246.

\author{
eProQuest document link
}

\section{ABSTRACT}

Over the past century, and especially after the 1970s, rainfall observations show an increase (decrease) of the wet summer (winter) season rainfall over northwest (southwest) Western Australia. The rainfall in central west Western Australia (CWWA), however, has exhibited comparatively much weaker coastal trends, but a more prominent inland increase during the wet summer season. Analysis of seasonally averaged rainfall data from a group of stations, representative of both the coastal and inland regions of CWWA, revealed that rainfall trends during the 1958-2010 period in the wet months of November-April were primarily associated with El Niño-Southern Oscillation (ENSO), and with the southern annular mode (SAM) farther inland. During the wet months of May-October, the Indian Ocean dipole (IOD) showed the most robust relationships. Those results hold when the effects of ENSOor IOD are excluded, and were confirmed using a principal component analysis of sea surface temperature (SST) anomalies, rainfall wavelet analyses, and point-by-point correlations of rainfall with global SST anomaly fields. Although speculative, given their long-term averages, reanalysis data suggest that from 1958 to 2010 the increase inCWWAinland rainfall largely is attributable to an increasing cyclonic anomaly trend over CWWA, bringing onshore moist tropical flow to the Pilbara coast. During May-October, the flow anomaly exhibits a transition from an onshore to offshore flow regime in the 2001-10 decade, which is consistent with the observed weaker drying trend during this period. [PUBLICATION ABSTRACT]

\section{FULL TEXT}

\section{Headnote}

\section{ABSTRACT}

Over the past century, and especially after the 1970s, rainfall observations show an increase (decrease) of the wet summer (winter) season rainfall over northwest (southwest) Western Australia. The rainfall in central west Western Australia (CWWA), however, has exhibited comparatively much weaker coastal trends, but a more prominent inland increase during the wet summer season. Analysis of seasonally averaged rainfall data from a group of stations, representative of both the coastal and inland regions of CWWA, revealed that rainfall trends during the 1958-2010 period in the wet months of November-April were primarily associated with El Niño-Southern Oscillation (ENSO), and with the southern annular mode (SAM) farther inland. During the wet months of May-October, the Indian Ocean dipole (IOD) showed the most robust relationships. Those results hold when the effects of ENSOor IOD are excluded, and were confirmed using a principal component analysis of sea surface temperature (SST) anomalies, rainfall wavelet analyses, and point-by-point correlations of rainfall with global SST anomaly fields. Although speculative, given their long-term averages, reanalysis data suggest that from 1958 to 2010 the increase inCWWAinland rainfall largely is attributable to an increasing cyclonic anomaly trend over CWWA, bringing onshore moist tropical flow to the Pilbara coast. During May-October, the flow anomaly exhibits a transition from an 
onshore to offshore flow regime in the 2001-10 decade, which is consistent with the observed weaker drying trend during this period.

1. Introduction

Relationships between rainfall variability in Western Australia (WA) and large-scale climate drivers have been studied extensively. The climate drivers include the Antarctic Oscillation (AAO), also known as the southern annular mode (SAM; Gong and Wang 1999; Thompson and Solomon 2002; Nan and Li 2003); El Niño-Southern Oscillation (ENSO) and ENSO-related standard indices such as Niño-1-4 and El Niño Modoki (Ashok et al. 2007); the Indian Ocean dipole (IOD; Saji et al. 1999; Webster et al. 1999); the Madden-Julian oscillation (MJO; Wheeler and Hendon 2004); and atmospheric blocking (Coughlan 1983; Mclntosh et al. 2008). These drivers have been investigated over the past two decades owing to the impacts of the observed changes and regional variations in rainfall trends. Because of its relatively larger population, the vast majority of studies of WA rainfall hitherto have focused largely on southwest Western Australia (SWWA), revealing significant insights into the physical mechanisms behind the observed long-term rainfall deficit, especially since the early 1970s. Because of its much smaller population, relatively fewer studies have focused on the contrasting increase in rainfall observed over northwest Western Australia (NWWA) during the same period [Fig. 1, courtesy of the Australian Bureau of Meteorology (BoM)]. However, to the authors' knowledge there have been no studies dedicated to the central west Western Australian region (CWWA), defined here as the area enclosed within 208-308S, coast-1208E (Fig. 1). Rainfall trends are influenced both by the wet months of November to April (NOVAPR) in north and central CWWA (latitude ;208-258S), and by the wet months of May to October (MAYOCT) in south CWWA (latitude ;308S). For these reasons, a succinct overview of the current state of knowledge of the relationships between rainfall variability and large-scale climate drivers in NWWA and SWWA is presented, following a brief introduction highlighting the importance of the CWWA region.

In recent years, both coastal and inland CWWA have experienced important socioeconomic growth. In the last several decades, the mining industry growth has warranted the construction and expansion of existing ports and railways, particularly near Port Hedland and, more generally, the Pilbara region of CWWA. Agriculturally, the semiarid climate of CWWA primarily is used for sheep and cattle grazing, whereas the coastal region has a major fishing industry (http://www.pdc.wa. gov.au). The value of the oil, gas, and mining industries alone is estimated to be over 70 billion U.S. dollars (http://www.pdc.wa.gov.au). Demands for CWWA resources have increased during the last half-century, related to the increased demand from a growing population in Australia and worldwide. A recent boom in these industries in CWWA has led to an increase in reliable, sustainable water supply needs (Stokes et al. 2008). Rainfall trends for inland CWWA during the last few decades have shown an overall increase during the wet summer season [December-February (DJF)], with comparatively weak drying trends along the coast (Figs. 1 and 2). These recent changes in rainfall patterns remain critical for freshwater supply to population growth and for resource and ecological sustainability. Further complicating the problem are the impacts of tropical lows, including landfalling tropical cyclones (TCs), the rainfall from which often comprises of the bulk of the total annual precipitation in the otherwise arid CWWA (e.g., Pook et al. 2012). In particular, the Pilbara coast near Port Hedland (PH in Fig. 2) has experienced more landfalling tropical systems than any other part of Australia, thereby posing a major threat to the local onshore and offshore mining and fishing industries, peaking during the month of February (http://www.bom. gov.au/cyclone/history/wa/pthed.shtml). This is particularly the case for inland CWWA, where wet summer season (DJF) rainfall has been increasing since the 1970s (Fig. 1b). Finally, in ecological terms,CWWAis home to world heritage sites and wildlife parks. For example, Shark Bay entered the World Heritage list in 1991 as a host site for endangered species.

Since the early 1970s there has been a positive trend (increase) in average annual rainfall overNWWAwhile, in the same time period, decadal-scale droughts have affected much of Australia (Fig. 1 and BoM). Long-term rainfall over southern Australia, including SWWA, is projected to decrease further in the next decades (BoM; http://www.climatechangeinaustralia.gov.au/natrain10. php). The drought in SWWA (Fig. 1) already has produced a chronic freshwater deficit, with associated impacts on both urban and rural areas (Solomon et al. 2007; Bureau 
of Meteorology 2010).

The influence of ENSO on Australian rainfall has long been known (e.g., Walker 1923; Nicholls 1985; Risbey et al. 2009; Cai et al. 201 1b,d,e). El Niño (La Niña) events are associated with anomalously low (high) rainfall over most of eastern Australia (e.g., McBride and Nicholls 1983; Ropelewski and Halpert 1987; Timbal et al. 2006; Wang and Hendon 2007; Ashok et al. 2007; Chowdhury and Beecham 2010; Speer et al. 2011). The connection between Indian Ocean sea surface temperature (SST) and Australian rainfall variations was shown by Nicholls (1989), Ashok et al. (2007), and Ummenhofer et al. (2008). Recent research focusing on WA has sought to determine the influence of SST fields from their impact on IOD events (Webster et al. 1999; Saji et al. 1999; Cai et al. 2011b,d,e). These studies have linked IOD with Australian winter rainfall variations, stretching from the northwest to the southeast of the continent (e.g., Ashok et al. 2003; Saji and Yamagata 2003; England et al. 2006; Ashok et al. 2007; Ummenhofer at al. 2008, 2009; Risbey et al. 2009; Murphy and Timbal 2008; Hope et al. 2010). Ummenhofer et al. (2008) found that Indian Ocean SST anomalies extend beyond correlations, to actually forcing variations in SWWA precipitation. To the south, SAM is the dominant mode of the Southern Hemisphere (SH) extratropical circulation, operating beyond the weather scale (Kidson 1988; Karoly 1990; Hartmann and Lo 1998; Easterling et al. 2000; Thompson et al. 2000; Li et al. 2005; Meneghini et al. 2007; Risbey et al. 2009). Although its precise role in SWWA drying trends still remains ambiguous, the SAM has been linked to annual and decadal rainfall variations over SWWA (e.g., Allan and Haylock 1993; Cai and Cowan 2006; Meneghini et al. 2007; Hendon et al. 2007a; Feng et al. 2010a; Cai et al. 2011c), while other studies have examined the connection between SWWA rainfall and the Indian Ocean (e.g., Simmonds 1990; Simmonds and Rocha 1991; Smith et al. 2000; Ashok et al. 2003; Samuel et al. 2006; Verdon and Franks 2005; Risbey et al. 2009; Cai et al. 2011b,d,e). Tenant and Reason (2005) have suggested that there is a teleconnection between South African and SWWA rainfall variability by analyzing circulation archetype frequency and the atmospheric energy cycle in the Southern Hemisphere. In contrast to many other studies, Feng et al. (2010b) posited that a large portion of the long-term drying trend over SWWA possibly is explained by the evolution of a well-coupled southwest Australian monsoon-like circulation (or SWAC). The well-coupled SWACSWWA rainfall relationship is largely independent the leading climate drivers such as SAM, IOD, and ENSO. Finally, the recent decline in SWWA wet winter season [June-August (JJA)] rainfall also could be accounted for by a gradual decline of the mean rainfall from the individual cutofflows, which generate $; 60 \%$ of the total rainfall in the area (Pook et al. 2012).

Several studies have highlighted the relevance of atmospheric blocking on Australian annual rainfall variability, measured by a blocking index defined by BoM (Pook andGibson 1999;Risbey et al. 2009). Blocking was shown to influence primarily the southern Australian region with the rainfall amount controlled by the specific position of the high-amplitude ridge (Pook and Gibson 1999; Pook et al. 2006). Blocking near 1408Ewas shownto support rainfall over southeast Australia, while blocking near the Great Australian Bight yielded to enhanced rainfall primarily in the SWWA region (Risbey et al. 2009).

While relatively little is known about the drivers of rainfall variability over NWWA (Shi et al. 2008; Cai et al. 2011a), a recent study by Lin and Li (2012) suggested that NWWA rainfall trends were teleconnected with SST variability in the tropical Atlantic region via the propagation of Rossby wave trains, inducing an upper tropospheric anticyclone anomaly over Australia. This upper-level anticyclone and associated divergence aloftproduces an increased largescale upward motion in NWWA, and hence rainfall in the area. Moreover, NWWA(and,more generally, northernAustralian) rainfall also ismodulated byMJOevents (e.g.,Hendon et al. 2007b; Wheeler et al. 2009), which act on much shorter time scales than the other climate drivers impacting this region.

The formation of TCs is modulated by the evolution of individual MJO and ENSO events (e.g., Camargo et al. 2007, 2009), with the rainfall accompanying those systems often producing the vast majority of the total annual precipitation, particularly in arid inland CWWA (Stokes et al. 2008; Pook et al. 2012). While there are no observable trends in the number of TCs (or intense TCs) over the past half-century, year-to-year TC (and tropical low) activity exhibits a high degree of variability (BoM; Ramsay et al. 2008; Pook et al. 2012).

As mentioned above, Speer et al. (2011) have investigated variability and trends in east Australian coastal rainfall. 
The methodology employed in that study included wavelet analyses of rainfall time series and Australian region atmospheric circulation anomalies, which also forms the basis for this study and this approach is applied to the variability and trends in CWWA rainfall during the 1958-2010 period. The present study has sections analyzing rainfall variability through a description of rainfall mechanisms and teleconnections of rainproducing systems, wavelet analyses of rainfall, bootstrap correlations and partial correlations, principal component (PC) analysis of global SSTs, and identification of Australian region atmospheric circulation anomalies, followed by concluding comments.

\section{Data and methodology}

The station monthly rainfall time series used in this study are compiled from high-quality rainfall datasets well suited for monitoring long-term trends and variability in Australian rainfall (Jones and Weymouth 1997; Lavery et al. 1997), made available to the public by BoM (http://www.bom.gov.au/climate/data/index.shtml). The rainfall stations, listed in Table 1, were selected to minimize missing data during the analysis period (1958-2010). Rainfall data for the later months were not included owing to pending assessment of quality control by BoM. The few missing monthly rainfall data $(, 0.75 \%)$ were simply filled by the average of the rainfall over the whole time period. The monthly rainfall data are evaluated in three ways. First, the rainfall time series are correlated with the indices from several key climate drivers, namely the quasi-biennial oscillation (QBO), SAM, the Southern Oscillation index (SOI), IOD, and ENSO-related indices, using a bootstrap sampling technique to determine the significance of those correlations (e.g., Wilks 2006; Li and Smith 2009). Because the influence of blocking in the CWWA region is marginal (Risbey et al. 2009), it was not explored here. In addition, it was decided not to assess the role of MJO events because its impact is confined almost entirely to the north of the CWWA region (Wheeler et al. 2009; Risbey et al. 2009).

The correlations were carried out on 6-month averaged data for the wet periods of NOVAPR and MAYOCT, which are the primary rainfall modes inCWWA(BoM). While higher-order climatic influences (less than 6 months) on Australian rainfall patterns were shown to exist (e.g., Kamruzzaman et al. 2013), this issue is deferred to future work. To avoid any relationship that may arise from trends in rainfall as well as in the climate drivers (e.g., Nicholls 2008), all of these data were detrended prior to computing the correlations. The intensity of IOD events, defined by the dipole mode index (DMI), is determined by the difference in SST between the western equatorial Indian Ocean (108S-108N, 508-708E) and the southeastern equatorial Indian Ocean (108S-08N, 908-1 108E), following Saji et al. (1999). Because the effect of ENSO on Australian rainfall is modulated by IOD phases (Risbey et al. 2009; Cai et al. $2011 \mathrm{~b}, \mathrm{~d}, \mathrm{e})$, the same methodology was applied to partial correlations between DMI and the various ENSO-related atmospheric (SOI)- and SST-based standard indices. The SSTbased indices are Niño-1.2 (108S-08, 908W-808W), Niño-3 (58S-58N, 1508-908W), Niño-3.4 (58S-58N, 1708-1208W), Niño-4 (58S-58N, 1608E-1508W), and El Niño Modoki [EMI; see definition in Ashok et al. (2007)]. DMI was computed using the areal averaged monthly Hadley Centre Global Sea Ice and Sea Surface Temperature (HadISST) dataset. With exception of EMI (http://www. jamstec.go.jp/frcgc/research/d1/iod/modoki_home.html. en), all SST-based ENSO indices (http://www.cpc. ncep.noaa.gov/data/indices) were calculated using the global National Oceanic and Atmospheric Administration (NOAA) Extended Reconstructed SST (ERSST) V3b dataset (Smith et al. 2008). Only the anomalies of all the aforementioned indices were considered herein. This study uses SAM as defined in Nan and Li (2003). These correlations, although not providing direct evidence of causal links given the nonlinearity of the system, are useful in suggesting where to search for possible climate drivers. They also indicate patterns, such as dipoles, in these potential links. As a second step, the smoothed 6-month averaged rainfall data were correlated with the ERSST V3b dataset (publicly available at http://www. cdc.noaa.gov/cdc/data.noaa.ersst.html) to establish potential links with ocean-driven climate drivers, with a focus on SST-based ENSO indices and the IOD. This dataset was shown to be acceptably reliable after 1940 (Smith et al. 2008) and SST anomalies relative to each month were computed. As a third step, a covariance-based principal component analysis was conducted on the same SST anomaly data (1958-2010 period) for NOVAPR and MAYOCT focused on the Pacific Ocean and Indian Ocean individually. With the annual cycle on the SST removed, the PCs were rotated using the varimax technique (Kaiser 1958; Richman 1986). 
To extract the dominant modes of variability, a covariance-based PC analysis is performed. After assessment of the congruence of their loading patterns in each case (Richman and Lamb 1985), only the two leading modes (with respect to total domain variance) are retained for rotation. Themotivation for this analysis is to underline the presence of ENSO in NOVAPR and of the IOD/DMI in MAYOCT.

Fourth, a Morlet wavelet analysis is carried out on the 6-month averaged data for each of the 10 stations shown in Fig. 2. Wavelet analysis projects a time series into time-frequency space, providing information about the amplitude of any periodic signals embedded in the time series (Klees and Haagmans 2000). In particular, wavelet analysis shows how the periodic signals change with time. Finally, the power of various scales also is obtained as a function of time, by computing the square of the amplitude. Here, open source code (http://paos.colorado. edu/research/wavelets/) is used to plot the relative power spectrum as a function of period and time, and the time averaged power as a function of period.

Finally, composite atmospheric circulation anomalies are derived from the National Centers for Environmental Prediction (NCEP)-National Center for Atmospheric Research (NCAR) reanalysis data (Kalnay et al. 1996), with plots provided by the NOAA Earth System Research Laboratory (ESRL) Physical Sciences Division (Boulder, Colorado; http://www.cdc.noaa.gov/). Circulation anomalies relative to 1981-2010 to match the new climate normal period are discussed for three time windows within the period 1958 to 2010 to provide a possible physical explanation of the observed rainfall trends.

3. Rainfall mechanisms and teleconnections

a. Correlation analysis

The rainfall time series for the five coastal CWWA stations show overall weak trends during NOVAPR and a marginal decrease during MAYOCT (Figs. 3a-e). While similar weak rainfall trends are seen for inland stations during MAYOCT, the NOVAPR period shows a large rainfall increase that is most evident for the northernmost stations (namely Coolawanyah and Mulga Downs; Figs. 2 and 3f-j). Most importantly, Fig. 3 confirms thatCWWAreceives the bulk of its rainfall during the summer months (e.g., Pook et al. 2012). The rainfall data exhibit large annual variability, particularly for the two northernmost stations and for Mulga Downs (Figs. 3a,f,g). Similar trends were seen for other nearby stations (not shown). While more stations could have been selected it was decided that the 10 stations selected herein (Table 1) are highly representative of the rainfall trends found within the key areas of CWWA (Fig. 1).

Because the rainfall trends in CWWA are largely attributed to NOVAPR rainfall variability, the latter period will be the focus of the remainder of the analysis. Results for MAYOCT will also be presented for comparison and completeness.

As mentioned in section 2, the analysis was performed using 6-month averaged data, and therefore future reference to the data in the text should be regarded as such unless otherwise specified. As a first step, rainfall time series were correlated with various climate driver indices known to influence rainfall trends in the SWWA and NWWA regions, respectively. This choice was motivated by the geographical location of CWWA, which straddles both SWWA and NWWA. Two types of correlations were initially carried out, namely the classical Pearson's method and the Spearman "rank" method. The latter choice was motivated by the high rainfall variability observed in some of the selected stations (e.g., Figs. 3a,f,g). The results revealed, however, that with the exception of a few isolated cases, the correlations obtained with both methods remained within 60.05 of each other. This result also held for median correlations obtained using a 1000-sample bootstrap technique for each station. Consequently, and for the sake of brevity, only the results obtained with Pearson's method will be shown, and these will be referred to as correlations.

Figure 4 presents "box and whisker" plots for a 1000- sample bootstrap of the NOVAPR rainfall data correlated with various climate indices known to influence the SWWAandNWWAregions (e.g., Risbey et al. 2009).A similar analysis was conducted for QBO, but showed comparatively weak, statistically insignificant correlations for both seasons and therefore will be omitted for the remainder of this analysis. The median correlation values are considered to be statistically significant whenever the $5 \%-95 \%$ percentile interval lies entirely on one side of the zero line, 
highlighted as a thick black horizontal line in Fig. 4.

The relatively weak relationship seen between SAM and the five coastal rainfall stations (Fig. 4a) is consistent with Risbey et al. (2009). Near the eastern boundary of the study domain (i.e., near 1208E; Fig. 1), SAM shows overall noteworthy correlationswith inland rainfall during NOVAPR (Fig. 4a; compare coastal and inland stations), a result that is also consistent with Risbey et al. (2009).

The most robust relationships for the NOVAPR season were found for SOI with both coastal and inland stations with positive median correlations values ranging between about 0.18 and 0.50 (Fig. 4c). Noteworthy relationships were also found between coastal stations and Niño-1.2, Niño-3, Niño-3.4, and Niño-4, respectively, with median correlation values as large as 20.50 (Figs. 4e-h). The similarity of the results between the SST-based ENSO indices is not surprising considering their high mutual correlations for both NOVAPR and MAYOCT (ranging between $r 5$ 0.77 and 0.94; not shown). The above results are in agreement with previous work (e.g., Risbey et al. 2009; Ashok et al. 2007). Because the SOI relates to the atmospheric "mass" component (i.e., pressure) of ENSO and not the ocean (SST), the former is a more reliable result given lower confidence in the early SST records (especially prior to the mid-1970s). Risbey et al. (2009) also noted that generally higher correlations of rainfall with SOI compared with SST-based ENSO indices were likely a consequence of atmospheric pressure being more directly related to the occurrence of rainfall than SST.

A similar analysis for MAYOCT revealed that the most robust relationship was found between DMI and both inland and coastal stations, with median correlations ranging between 20.18 and 20.41 (Fig. 5b). In contrast to NOVAPR, all ENSO-related indices showed nonsignificant correlations statistics with the coastal stations (Figs. 5c-h). Note also that the relatively strong correlations existing between SAM and inland stations in NOVAPR are not seen during MAYOCT (Figs. 4a and 5a). The relationship between DMI and CWWA MAYOCT rainfall is in agreement with other studies focusing on WA (e.g., Ashok et al. 2003; Verdon and Franks 2005; Samuel et al. 2006; Cai et al. $2011 \mathrm{~b}, \mathrm{~d}, \mathrm{e})$. This result also highlights the seasonal variability of the influence of large-scale remote climate drivers on the rainfall, which also was reported for many other regions of the Australian continent (e.g., Ashok et al. 2003; Saji and Yamagata 2003; England et al. 2006; Ashok et al. 2007; Ummenhofer at al. 2008; Risbey et al. 2009; Speer et al. 2011). Consistent with our results, Cai et al. (2011b) found that the great majority (79\%) of the median Austral winter rainfall trend is attributable to IOD, and the decline (Figs. 1 and 3 ) was suggested to be a direct consequence of the positive phases of IOD trending upward in recent decades, which appears likely to persist (Cai et al. 2011b). The upward trend was hypothesized as being a direct response of the IndianOcean SST field to climate change and global warming (Fourth Assessment Report of the Intergovernmental Panel on Climate Change; Cai et al. 2009). This suggestion is consistent with earlier work by Streten (1981) and Nicholls (1989), who found that droughts over the Australian continent were associated with negative SST anomalies in the eastern Indian Ocean (and therefore indicative of a positive IOD phase).

Previous studies have highlighted the complex coupling between the wet summer rainfall (DJF) and positive/ negative phases of IOD and ENSO, with the negative IOD and no ENSO years being associated with the largest positive rainfall trends inWA(and CWWA; see Fig. 7 in Risbey et al. 2009). Regardless of the phase of IOD, La Niña was shown always to lead to above average rainfall over Australia (Power et al. 2006) during the wet summer months (DJF). This result remains consistent with the negative correlations obtained between SST-based ENSO indices and coastal stations. There is, however, ongoing debate about the extent to which IOD and ENSO are independent of each other (e.g., Meyers et al. 2007; Cai et al. 2011b,d,e). Further complicating the problem of dependency between these two climate drivers, MJO was shown also to interact with ENSOby enhancing periods of dry breaks duringEINiño years (e.g., Hendon et al. 2007b). While our study period (1958-2010) combines both negative and positive phases of either IOD or ENSO, the aforementioned temporal variations will be masked in the present correlation analysis. Because this aspect was already well covered by Meyers et al. (2007) and Risbey et al. (2009), it is not necessary to repeat a similar detailed analysis. Instead, the wavelet analysis shown below was partially designed to complement the correlation analysis, by offering a spectral evolution as a function of time to highlight periods of the known positive (negative) IOD (ENSO) phases with high (low) power hidden within the 
individual station rainfall time series.

Because of the interplay between IOD and ENSO in modulating the rainfall over Australia (e.g., Cai et al. 2009, $2011 \mathrm{~b}, \mathrm{~d}, \mathrm{e})$, partial correlations between the aforementioned ENSO indices and DMI were computed for NOVAPR

(Fig. 6) and MAYOCT (Fig. 7). As the correlations between SST-based Niño indices are large (r5 0.80-0.94), the results obtained with those indices not surprisingly are similar (Figs. 4e-h and 5e-h). Therefore, for simplicity, only partial correlations between DMI and the SST-based Niño index having the highest partial correlations, namely Niño-3, are shown.

During NOVAPR, the most robust relationships again are found for Niño-3, excluding the effect of DMI (Niño-3jDMl; Fig. 6f) and SOI excluding DMI (SOljDMI; Fig. 6d). These strong relationships were again best seen for the coastal stations with inland stations having overall less significant relationships (Figs. 6d, f). The weak relationships obtained earlier with DMI alone (Fig. 4b) were not improved when the effect of ENSOrelated indices were removed (Figs. 6a-c).

Consistent with the results obtained in Fig. 5,MAYOCT partial correlations for DMI indicate comparable negative median correlations (20.18 to 20.45) when ENSO components are removed (Figs. 7a-c). Removing the effects of DMI from each ENSO component did not improve the correlation statistics (Figs. 7d-f). This confirms the robustness of the relationship between $\mathrm{DMI}$ and the inland and coastal stations obtained earlier, a finding that is consistent with earlier studies (Cai et al. $2011 \mathrm{~b}, \mathrm{~d}, \mathrm{e}$ ). With their analysis primarily highlighting the largest impact of IOD/ENSO during the austral winter affecting southern Australia, Cai et al. (2011e) suggested that the effect of ENSO was minimal because ENSO is largely unrelated to the IOD in MAYOCT, a speculation that also seems valid for the CWWA region (compare Fig. 5b and Figs. 7a-c).

It is relevant to stress, again, that correlation-based analyses are by definition circumstantial rather than causal, for example because of the nonlinearities and coupling proper to the atmosphere-ocean system. For this reason, several other analysis methods are presented below to complement the aforementioned analysis and assess the robustness of the results.

b. Relationships with global sea surface temperatures

With the exception of SOI, all other climate indices having statistically significant relationships with the rainfall either inNOVAPR orMAYOCTare SST based (Figs. 4-7). To further assess the robustness of those relationships, the coastal and inland-averaged rainfall anomaly time series for all rainfall stations were spatially correlated (i.e., point by point) for both seasons with NOAA SST anomaly time series (Fig. 8). Figure 8 was purposely telescoped over the Pacific and Indian Ocean basins to focus on ENSO and IOD, which were shown to have the strongest relationships with CWWA rainfall. Similar maps were created for each of the 10 stations for both seasons (and also for different decades) and showed similar trends to the composites presented in Fig. 8. Only significant correlations at the $95 \%$ confidence interval are shown, namely jrj\$0.30, a value which was determined via a 1000 sample bootstrap analysis of the correlations at each point on the map.

The NOVAPR correlation maps show a well-defined "horseshoe" correlation pattern with the SSTs in the equatorial Pacific Ocean (Figs. 8a,b), a pattern that has been long recognized to be associated with ENSO (e.g., Guan and Nigam 2008). Negative (positive) correlations in the central equatorial Pacific would be indicative of negative (positive) SST anomalies and hence there is a direct correspondence with the SST horseshoe pattern. The horseshoe pattern in NOVAPR is also stronger for the coastal stations and is consistent with the results obtained earlier (Figs. 5 and 7). The increasing NOVAPR rainfall trends seen along the coast in Figs. 3f-j also exhibit high correlations with the SST field near coastal CWWAand SWWA. However, duringMAYOCT, the ENSO-related horseshoe pattern in the equatorial Pacific Ocean disappears, consistent with the weak relationships obtained earlier with ENSO (Fig. 6). MAYOCT is primarily characterized with positive SST correlations south of Indonesia/East Timor and offthe Pilbara coast (Figs. 8c,d). Because the correlations with the SST field near Ethiopia remain small (Figs. 8c,d), the rainfall is correlated with a negative difference between the western and eastern SST field in the Indian Ocean, a result consistent with negative correlations obtained earlier with IOD (DMI; Figs. 6 and 7). In summary, theMAYOCT rainfall is positively correlated with negative phases of IODwhereas 
inNOVAPRthe rainfall is positively correlated with negative phases of ENSO or La Niña. These findings are consistent with Risbey et al. (2009) and Meyers et al. (2007).

c. Principal component analysis of Indian Ocean and Pacific Ocean sea surface temperatures

To further assess the relationships of CWWA rainfall with the global SST anomalies obtained in the previous section, a covariance-based PCA was conducted on SST anomalies of the V3b dataset (1958-2010 period) focused on the Pacific Ocean and Indian Ocean individually for both NOVAPR and MAYOCT. As mentioned in the methodology section, the rationale for this analysis is to complement the relationships obtained with the correlations, namely to underline the presence of ENSO in NOVAPR and IOD/DMI in MAYOCT.

The varimax-rotated spatial loadings of the first principal component $(\mathrm{PC1})$ show a clear ENSO signal in both seasons (Figs. 9a,b) with a total domain variance explained of $29.2 \%$ in NOVAPR and $20.7 \%$, in MAYOCT, result consistent with previous work (e.g., Barlow et al. 2001; Ramsay et al. 2008). The larger total domain variance for PC1 in NOVAPR (by 8.5\%) supports the statistically significant correlations with rainfall obtained in NOVAPR compared with MAYOCT (Figs. 4 and 5), as well as the stronger ENSO correlation pattern of rainfall with SST anomalies in NOVAPR compared with MAYOCT (Fig. 8). Figures $9 \mathrm{c}$ and $9 \mathrm{~d}$ depict a welldefined dipole pattern in the Indian Ocean, although the geographical location does not match exactly that of the IOD (Saji et al. 1999; Webster et al. 1999). However, Fig. 9d reveals larger loading patterns southwest and west of Java, Indonesia, and smaller loadings near the horn of Africa in MAYOCT. This spatial loading pattern in MAYOCT is more consistent with IOD. The dipoles in both seasons are consistent with the SST anomaly patterns reported in Ummenhofer et al. (2009).

The spatial loading patterns for the second principal component (PC2) also reveal a well-defined ENSO horseshoe pattern in the Pacific, also more pronounced in NOVAPR (Figs. 10a,b). The total variance explained for PC2 in the Pacific is $8.5 \%$ during both MAYOCT and NOVAPR. The Indian Ocean dipole pattern evident in PC1 (Figs. 9c,d) is also seen for PC2 (Figs. 10c,d) with a total domain variance of $9.6 \%$ in NOVAPR and $8.4 \%$ in MAYOCT. Loadings for higher-order PCs (i.e., 3 and beyond) for both NOVAPR and MAYOCT revealed comparatively smaller total domain variances in both basins (not shown).

d. Rainfall wavelets analysis

Figure 11 shows wavelet power spectra and global spectra for NOVAPR for the coastal regions and their averages. Signals below the $5 \%$ significance level are considered to be spurious and therefore only spectral powers enclosed within this contour are discussed. Because of its irregular nature and overall lack of periodicity, at least in the time period considered, it remains difficult to isolate the IOD in the global wavelet spectrum alone. All five coastal stations indicate a welldefined 2-4-yr periodic signal in the global spectrum (Figs. 11a-e), which not surprisingly also appears in their average (Fig. 11f). Similar results are seen for inland stations (Fig. 12). Following the analysis shown earlier, this would be consistent with the presence of an ENSO signal, as the 2-4-yr signal appears more consistently for the coastal stations than for inland stations (cf. Figs. 11 and 12), which is alluded to in the earlier correlations (Figs. 4d-f). All 10 stations have relatively high 2-4-yr power between 1998 and 2000, which are years associated with strong La Niña events and hence above average rainfall over WA (Meyers et al. 2007; Risbey et al. 2009). The high power seen in the coastal stations prior to the mid-1970s is not seen in all the inland stations (cf. Figs. 11 and 12). However, because coastal stations were shown to exhibit more robust correlations with SSTbasedENSOindices duringNOVAPR(Figs. 4 and 6), the early values of strong power seen in Fig. 11 could also be associated with ENSO. For instance, the 1970-76 period was associated with several strong La Niña events and one strong El Niño event (in 1972/73), which could account for the high power seen in Fig. 11 during this time period. The years 1961, 1965, and 1993 were the only years in our dataset characterized by a simultaneous negative phase of IODand weak ENSO, which, as shown by Risbey et al. (2009), are associated with the largest positive rainfall anomalies in CWWA (their Fig. 7). The averaged power spectra for both inland and coastal stations in NOVAPR (Figs. 10 and 11) show that, generally, those three years were all associated with high power.

Earlier analysis revealed that during MAYOCT, DMI (IOD) showed the most robust relationship with all CWWA rainfall stations, and essentially remained unchanged when ENSO-related indices were removed. The global power 
spectra for both coastal (Fig. 13) and inland stations (Fig. 14) show a consistent but weaker 2-4-yr signal and a stronger 8-yr signal straddling the $5 \%$ significance level. To determine whether this 8-yr signal is significant, the wavelet analysis was recomputed on the rainfall time series starting at 1945 instead of 1958 (not shown). Those indicated that the 8-yr signal remains within the $5 \%$ significance variance level with a magnitude comparable with that of the 2-4-yr signal. This indicates that the lack of significance seen for data starting at 1958 was primarily a consequence of having a time period too small to fit several 16-yr wavelengths. The analysis presented earlier suggested an overall weak relationship between ENSO and rainfall in MAYOCT, which appeared most clearly in the spatial correlation with SST fields. Therefore, it is hypothesized that both the 2-4-yr and the 8-yr signal seen in the wavelet power spectra might be associated with the irregular nature of IOD (Saji et al. 1999, their Fig. 1).

4. Circulation anomalies

It is relevant to stress that the results of this section are based on multimonth, multiyear averages and, consequently, those may not be entirely representative of the actual circulations accompanying rainfall events across the periods. As such, some of this analysis is speculative in nature. It was found, however, that despite this limitation the overall trends in terms of probability of precipitation arising from a given circulation anomaly were broadly consistent with the results from the aforementioned analysis and, therefore, will be briefly described. Figure 15 shows 850-hPa vector wind anomalies for both NOVAPR and MAYOCT during three different time intervals spanning the 1958 to 2010 period. The motivations behind this time partition are that 1) 1976 is a year associated in much of the literature with the onset of sharper climate changes (e.g., Thompson et al. 2008) and 2) 1999 was selected to highlight circulation changes during the last decades, the period associated with the most dramatic rainfall trends over the last century. The large-scale circulation patterns discussed in this section are very similar to those in the 40-yr European Centre forMedium-RangeWeather Forecasts (ECMWF) Re-Analysis (ERA-40) dataset. The NCEP data were chosen because they include rainfall and precipitationderived products, in contrast to the ERA-40 dataset.

The 850-hPa NOVAPR circulation anomalies during the first two time periods, namely 1958-76 and 1977-99 (Figs. $15 a, b)$, are characterized by a well-defined subtropical high just offthe coast of CWWA bringing offshore flow to the Pilbara coast and onshore winds near the Geraldton (Nabawa) region and SWWA. The larger wind speed anomalies apparent during the 1958-76 period are indicative of a stronger $850-\mathrm{hPa}$ high and are consistent with overall drier years seen in this region (Fig. 16a). Later, during 1977-99, the wind speed anomalies weaken, which is indicative of a weaker anticyclone, yielding to a weaker drying trend (Fig. 16b). Last, and perhaps most importantly, in the last decade (2000-10) this anticyclonic circulation anomaly is seen to shiftto a well-defined 850-hPa cyclonic pattern, bringing onshore moist tropical air to the Pilbara coast and offshore flow to SWWA. This cyclonic circulation pattern during the last decade is consistent withwetter trends in CWWA, particularly inland (Figs. 3 and 16c; also NWWA) and drier trends in SWWA (Fig. 16c). The exact physical mechanisms behind this cyclonic circulation anomaly remain unclear but could be associated with the occurrence of tropical lows during NOVAPR, the rainfall contribution from which has been shown to be important in this region (Pook et al. 2012). Analysis of the track of TCs in this region indicated a large degree of variability in the last half-century with no clear increase in landfalling named systems, consistent with Camargo et al. $(2007,2009)$ and Ramsay et al. (2008). A more consistent approach for future studies should take into account storm speed and storm size, which are both key in modulating local rainfall amounts.

During the MAYOCT period in 1958-76, 850-hPa wind anomalies reveal a strong onshore component in the CWWA and NWWA regions (Fig. 15a), which later weakens (1977-99; Fig. 15e). This incipient weakening of the onshore winds in CWWA is consistent with the wet trend observed during 1958-76 to decrease to nearzero levels later in 1977-99 (cf. Figs. 16d,e). In the last decade, the onshore wind anomalies over CWWA shifted from a weak onshore component to a weak offshore flow pattern, yielding to (and consistent with) a weak drying trend (Figs. $15 f$ and 16f). This weakening of the austral winter westerlies over WA was shown to be associated with the increasing occurrence of positive IOD phases in the last decades (Cai et al. 2011 e). Figures 15 and 16 together confirm that the rainfall regime in CWWA is dominated by two distinct modes with the NOVAPR rain accounting for the great 
majority of the trends, as seen in Fig. 3, providing further justification for dividing individual years into two rainfall modes rather than four seasons.

5. Conclusions

Analyzing correlations between relevant climate drivers indices and rainfall, combined with the use of global SST anomaly correlations with rainfall, principal component analysis, wavelet analysis of rainfall, and atmospheric circulation anomalies, enables us to elicit some of the reasons why, since the mid-1970s, there has been an increasing rainfall trend inNOVAPR over most of CWWA (especially inland CWWA) and a marginal drying trend during MAYOCT.

In the last two decades, several studies have augmented our knowledge of the relationships between the largescale climate drivers and the observed rainfall trends across Australia, with the great majority of these works focusing on SWWA and the southeast of the continent (Victoria and southeast New South Wales) owing to the larger population in those regions. This work is a logical follow-on to these studies by focusing on theCWWA region, which straddles the already welldocumented SWWA and NWWA regions.

The analysis revealed a seasonal relationship between CWWArainfall and ENSO-related indices (SOI with all stations; and SST-based Niño indices with coastal stations) in the NOVAPR season. Those correlations were negative (positive) for SST-based Niño indices (SOI). This result is consistent with La Niña years being the dominant years during the observed increase inCWWA rainfall. SAM was also shown to be important for inland stations near 1208E, consistent with recent work by Risbey et al. (2009). In MAYOCT, IOD was found to show the most robust (negative) correlations with coastal and inland stations rainfall. These seasonal relationships were confirmed by additional correlations analysis of the rainfall of individual stations and their coastal/ inland averages with global SST fields. The NOVAPR correlations map exhibited a well-defined horseshoe pattern in the Pacific, which is indicative of a similar SST pattern that has been long recognized as being associated with an ENSO signal. During the MAYOCT wet winter months, this horseshoe correlation pattern in the Pacific Ocean disappears while large positive correlations with SSTs appearing in the eastern Indian Ocean IOD region, leading to an association of rainfall trends with negative IOD years, as reported by Risbey et al. (2009).

Principal component analysis on SST anomalies for both seasons confirmed the existence of a dominant ENSO signal in the Pacific Ocean and a well-defined dipole pattern in the Indian Ocean consistent with SST patterns of earlier works (Ummenhofer et al. 2009). Specifically, it was found that the ENSO signal was the dominant mode during both NOVAPR and MAYOCT, with a PC1 total domain variance of $29.2 \%$ inNOVAPR and $20.7 \%$ in MAYOCT. The larger variance explained in NOVAPR compared with MAYOCT (by 8.5\%) is consistent with the correlation with the rainfall being statistically significant in NOVAPR and with a stronger horseshoe correlation pattern of the rainfall with the Pacific SST anomalies during this period. A similar result was seen in the Pacific SSTs for PC2 with a variance explained of $8.5 \%$ for both seasons. The same principal component analysis for the Indian Ocean revealed that the dipole pattern seen in PC1 and PC2 was shifted farther north near the geographical region of the IOD during MAYOCT, with a slightly higher variance explained for PC1 (25\% compared with $24 \%$ ).

The stronger association of ENSO with NOVAPR rainfall was confirmed by a wavelet analysis spectrum in NOVAPR, which is dominated by a 2-4-yr signal with the highest power occurring during ENSO years. In MAYOCT, both a 2-4-yr and an 8-yr peak dominate the global power spectra during years associated with negative IOD phases.

The circulation anomalies derived from reanalysis data revealed a distinct atmospheric pattern evolution in the last half century, which accounted for the observed CWWA rainfall trends for both wet rainfall seasons defined here. In NOVAPR, the wind vector/speed anomalies overCWWAprogressively shifts from a strong 850-hPa anticyclonic anomaly to weak cyclonic anomalies, yielding to the progressive increase of onshore advection of moist tropical air in the Pilbara coast and hence, increased rainfall. In MAYOCT, the wind anomalies showed a progressive weakening of the zonal onshore flow in the Pilbara coastal region of the CWWA, from a strong onshore component in the 1960s to 1970s to a weak offshore component during the last decade, which accounts for the wetter trend seen earlier in the mid-1960s shifting to a marginal drying trend in the last decade. 
Acknowledgments. Funding of this research largely was provided by the Australian SustainableDevelopment Institute, Curtin University, Perth, Western Australia. Funding was also provided by NOAA/Office of Oceanic and Atmospheric Research under NOAA-University of Oklahoma Cooperative Agreement NA080AR4320904, U.S. Department of Commerce. Computer resources were provided by the Oklahoma Supercomputing Center for Education and Research (OSCER) hosted at the University of Oklahoma. The authors also thank Dr.Michael Richman for valuable insights at an earlier stage of the manuscript. The authors would also thank Dr. Vimont and three anonymous reviewers for their critical comments, which helped improve the quality of the manuscript.

\section{References}

\section{REFERENCES}

Allan, R. J., and M. R. Haylock, 1993: Circulation features associated with the winter rainfall decrease in southwestern Australia. J. Climate, 6, 1356-1367.

Ashok, K., Z. Guan, and Y. Yamagata, 2003: Influence of the Indian Ocean dipole on the Australian winter rainfall. Geophys. Res. Lett., 30, 1821, doi:10.1029/2003GL017926.

H. Nakamura, and T. Yamagata, 2007: Impacts of ENSO and Indian OceanDipole events on the Southern Hemisphere stormtrack activity during austral winter. J. Climate, 20, 3147-3163.

Barlow, M., S. Nigam, and E. H. Berbery, 2001: ENSO, Pacific decadal variability, and U.S. summertime precipitation, drought, and stream flow. J. Climate, 14, 2105-2128.

Bureau of Meteorology, cited 2010: Annual Climate Statement 2010. [Available online at http://www.bom.gov.au/climate/ current/index.shtml.]

Cai, W., and T. Cowan, 2006: SAM and regional rainfall in IPCC AR4 models: Can anthropogenic forcing account for southwest Western Australian winter rainfall reduction? Geophys. Res. Lett., 33, L24708, doi:10.1029/2006GL028037. and M. Raupach, 2009: Positive Indian Ocean dipole events precondition southeast Australia bushfires. Geophys. Res. Lett., 36, L19710, doi:10.1029/2009GL039902.

A. Sullivan, J. Ribbe, and G. Shi, 2011 a: Are anthropogenic aerosols responsible for the northwest Australia summer rainfall increase? A CMIP3 perspective and implications. J. Climate, 24, 2556-2564.

A. Sullivan, T. Cowan, J. Ribbe, and G. Shi, 2011 b: Simulation of the Indian Ocean dipole: A relevant criterion for selecting models for climate projections. Geophys. Res. Lett., 38, L03704, doi:10.1029/2010GL046242.

P. van Rensch, S. Borlace, and T. Cowan, $2011 \mathrm{c}$ : Does the southern annular mode contribute to the persistence of the multidecade-long drought over southwest Western Australia? Geophys. Res. Lett., 38, L14712, doi:10.1029/2011GL047943.

and T. Cowan, $2011 \mathrm{~d}$ : Influence of global-scale variability on the subtropical ridge over southeast Australia. J. Climate, 24, 6035-6053.

and $\mathrm{H}$. H. Hendon, $2011 \mathrm{e}$ : Teleconnection pathways of ENSO and the IOD and the mechanisms for impacts on Australian rainfall. J. Climate, 24, 3910-3923.

Camargo, S. J., K. A. Emanuel, and A. H. Sobel, 2007: Use of a genesis potential index to diagnose ENSO effects on tropical cyclone genesis. J. Climate, 20, 4819-4834.

M. C.Wheeler, and A. H. Sobel, 2009: Diagnosis of the MJO modulation of tropical cyclogenesis using an empirical index. J. Atmos. Sci., 66, 3061-3074.

Chowdhury, R. K., and S. Beecham, 2010: Australian rainfall trends and their relation to the southern oscillation index. Hydrol. Processes, 24, 504-514.

Coughlan, M., 1983: A comparative climatology of blocking action in the two hemispheres. Aust. Meteor. Mag., 31 , 3-13.

Easterling, D. R., J. L. Evans, P. Ya. Groisman, T. R. Karl, K. E. Kunkel, and P. Ambenje, 2000: Observed variability and trends in extreme climate events: A brief review. Bull. Amer. Meteor. Soc., 81, 417-425.

England, M. H., C. C. Ummenhofer, and A. Santoso, 2006: Interannual rainfall extremes over southwest Western 
Australia linked to Indian Ocean climate variability. J. Climate, 19, 1948-1969.

Feng, J., J. Li, and Y. Li, 2010a: Is there a relationship between the SAM and southwest Western Australian winter rainfall? J. Climate, 23, 6082-6089.

and 2010b:A monsoon-like southwest Australian circulation and its relation with rainfall in southwest Western Australia. J. Climate, 23, 1334-1353.

Gong, D., and S. Wang, 1999: Definition of Antarctic oscillation index. Geophys. Res. Lett., 26, 459-462.

Guan, B., and S. Nigam, 2008: Pacific sea surface temperatures in the twentieth century: An evolution-centric analysis of variability and trend. J. Climate, 21, 2790-2809.

Hartmann, D. L., and F. Lo, 1998: Wave-driven zonal flow vacillation in the Southern Hemisphere. J. Atmos. Sci., 55, 1303- 1315.

Hendon, H. H., D. W. J. Thompson, and M. C. Wheeler, 2007a: Australian rainfall and surface temperature variations associated with the Southern Hemisphere annular mode. J. Climate, 20, 2452-2467.

M. C.Wheeler, and C. Zhang, 2007b: Seasonal dependence of the MJO-ENSO relationship. J. Climate, 20, 531543.

Hope, P., B. Timbal, and R. Fawcett, 2010: Associations between rainfall variability in the southwest and southeast of Australia and their evolution through time. Int. J. Climatol., 30, 1360- 1371.

Jones, D. A., and G. T. Weymouth, 1997: An Australian monthly rainfall dataset. Bureau of Meteorology Tech. Rep. 70, $19 \mathrm{pp}$.

Kaiser, H. F., 1958: The varimax criterion for analytic rotation in factor analysis. Psychometrika, 23, 187-200.

Kalnay, E., and Coauthors, 1996: The NCEP/NCAR 40-Year Reanalysis Project. Bull. Amer. Meteor. Soc., 77, 437471.

Kamruzzaman, M., S. Beecham, and A. V. Metcalfe, 2013: Climatic influences on rainfall and runoffvariability in the southeast region of the Murray-Darling basin. Int. J. Climatol., 33, 291-311, doi:10.1002/joc.3422.

Karoly, D. J., 1990: The role of transient eddies in low-frequency zonal variations of the Southern Hemisphere circulation. Tellus, 42A, 41-50.

Kidson, J. W., 1988: Interannual variations in the Southern Hemisphere circulation. J. Climate, 1, 1177-1198.

Klees, R., and R. Haagmans, Eds., 2000: Wavelets in the Geosciences. Springer, 241 pp.

Lavery, B., G. Joung, and N. Nicholls, 1997: An extended highquality historical rainfall dataset for Australia. Aust.

Meteor. Mag., 46, 27-38.

Li, Y., and I. Smith, 2009: A statistical downscaling model for southernAustralia winter rainfall. J. Climate, 22, 11421158.

W. Cai, and E. P. Campbell, 2005: Statistical modeling of extreme rainfall in southwest Western Australia. J. Climate, 18, 852-863.

Lin, Z., and Y. Li, 2012: Remote influence of the tropical Atlantic on the variability and trend in northwest Australia summer rainfall. J. Climate, 25, 2408-2420.

McBride, J. L., and N. Nicholls, 1983: Seasonal relationships between Australian rainfall and the Southern Oscillation. Mon. Wea. Rev., 111, 1998-2004.

McIntosh, P., M. Pook, J. Risbey, P. Hope, G. Wang, and O. Alves, 2008: Australia's regional climate drivers. Land and Water Australia Tech. Rep., 48 pp.

Meneghini, B., I. Simmonds, and I. N. Smith, 2007: Association between Australian rainfall and the southern annular mode. Int. J. Climatol., 27, 109-121.

Meyers, G. A., P. C. McIntosh, L. Pigot, and M. J. Pook, 2007: The years of El Niño, La Niña, and interactions with the tropical Indian Ocean. J. Climate, 20, 2872-2880.

Murphy, B., and B. Timbal, 2008: A review of recent climate variability and climate change in southeastern Australia. Int. J. Climatol., 28, 859-879.

Nan, S., and J. Li, 2003: The relationship between summer precipitation in the Yangtze River valley and the boreal spring Southern Hemisphere annular mode. Geophys. Res. Lett., 30, 2266, doi:10.1029/2003GL018381. 
Nicholls, N., 1985: Towards the prediction of major Australian droughts. J. Climatol., 5, 553-560.

1989: Sea surface temperature and Australian winter rainfall. J. Climate, 2, 965-973.

2008: Recent trends in the seasonal and temporal behaviour of the El Niño-Southern Oscillation. Geophys.

Res. Lett., 35, L19703, doi:10.1029/2008GL034499.

Pook, M. J., and T. Gibson, 1999: Atmospheric blocking and storm tracks during SOP-1 of the FROST project. Aust. Meteor. Mag., 48 (June special edition), 51-60.

P. McIntosh, and G. Meyers, 2006: The synoptic decomposition of cool-season rainfall in the southeastern

Australian cropping region. J. Appl. Meteor. Climatol., 45, 1156-1170.

J. S. Risbey, and P. C. McIntosh, 2012: The synoptic climatology of cool-season rainfall in the central wheat belt of Western Australia. Mon. Wea. Rev., 140, 28-43.

Power, S., M. Haylock, R. Colman, and X. Wang, 2006: The predictability of interdecadal changes in ENSO activity and ENSO teleconnections. J. Climate, 19, 4755-4771.

Ramsay, H. A., L. M. Leslie, P. J. Lamb, M. B. Richman, and M. Leplastrier, 2008: Interannual variability of tropical cyclones in the Australian region: Role of large-scale environment. J. Climate, 21, 1083-1103.

Richman, M. B., 1986: Rotation of principal components. Int. J. Climatol., 6, 293-335.

and P. J. Lamb, 1985: Climatic pattern analysis of three- and seven-day summer rainfall in the central United States: Some methodological considerations and a regionalization. J. Climate Appl. Meteor., 24, 1325-1343.

Risbey, J. S., M. J. Pook, P. C. McIntosh,M. C.Wheeler, and H. H. Hendon, 2009: On the remote drivers of rainfall variability in Australia. Mon. Wea. Rev., 137, 3233-3253.

Ropelewski, C. F., and M. S. Halpert, 1987: Global and regional scale precipitation patterns associated with El Niño/Southern Oscillation. Mon. Wea. Rev., 115, 1606-1626.

Saji, N. H., and T. Yamagata, 2003: Possible impacts of Indian Ocean dipole mode events on global climate. Climate Res., 25, 151-169.

B. N. Goswami, P. N. Vinayachandran, and T. Yamagata, 1999:Adipole mode in the tropical Indian Ocean. Nature, 401, 360-363.

Samuel, J. M., D. C. Verdon, M. Sivapalan, and S. W. Franks, 2006: Influence of Indian Ocean sea surface temperature variability on southwest Western Australian winter rainfall. Water Resour. Res., 42, W08402, doi:10.1029/2005WR004672.

Shi, G., W. Cai, T. Cowan, J. Ribbe, L. Rotstayn, and M. Dix, 2008: Variability and trend of North West Australia rainfall: Observations and coupled climatemodeling. J.Climate, 21, 2938-2959.

Simmonds, I., 1990: A modelling study of winter circulation and precipitation anomalies associated with Australian region ocean temperatures. Aust. Meteor. Mag., 38, 151-162.

and A. Rocha, 1991: The association of Australian winter climate with ocean temperatures to the west. J.

Climate, 4, 1147-1161.

Smith, I. N., P. McIntosh, T. J. Ansell, C. J. C. Reason, and K. Mclnnes, 2000: Southwest Western Australian winter rainfall and its association with Indian Ocean climate variability. Int. J. Climatol., 20, 1913-1930.

Smith, T. M., R. W. Reynolds, T. C. Peterson, and J. Lawrimore, 2008: Improvements to NOAA's historical merged land- ocean surface temperature analysis (1880-2006). J. Climate, 21, 2283-2296.

Solomon, S., D. Qin, M. Manning, M. Marquis, K. Averyt, M. M. B. Tignor, H. L. Miller Jr., and Z. Chen, Eds., 2007: Climate Change 2007: The Physical Science Basis. Cambridge University Press, 996 pp.

Speer, M. S., L. M. Leslie, and A. O. Fierro, 2011: Australian east coast rainfall decline related to large scale climate drivers. Climate Dyn., 36, 1419-1429, doi:10.1007/s00382-009-0726-1.

Stokes, C. J., and S. M. Howden, Eds., 2008: Anoverview of climate change adaptation in Australian primary industries-Impacts, options and priorities. CSIRO Rep., 348 pp.

Streten, N. A., 1981: Southern Hemisphere sea surface temperature variability and apparent associations with Australian rainfall. J. Geophys. Res., 86 (C1), 485-497.

Tenant, W. J., and C. J. C. Reason, 2005: Associations between the global energy cycle and regional rainfall in 
South Africa and southwest Australia. J. Climate, 18, 3032-3047.

Thompson, D. W., and S. Solomon, 2002: Interpretation of recent Southern Hemisphere climate change. Science, 296, 895-899.

, J.M. Wallace, and G. C. Hergel, 2000: Annular modes in the extratropical circulation. Part II: Trends. J.

Climate, 13, 1018- 1036.

J. Kennedy, J. Wallace, and P. Jones, 2008: A large discontinuity in the mid-twentieth century in observed global-mean surface temperature. Nature, 453, 646-649.

Timbal, B., J. M. Arblaster, and S. Power, 2006: Attribution of the late-twentieth-century rainfall decline in southwest Australia. J. Climate, 19, 2046-2062.

Ummenhofer, C. C., A. Sen Gupta, M. J. Pook, and M. H. England, 2008: Anomalous rainfall over southwest Western Australia forced by Indian Ocean sea surface temperatures. J. Climate, 21, 5113-5134.

A. S. Taschetto, and M. H. England, 2009: Modulation of Australian precipitation by meridional gradients in east Indian Ocean sea surface temperature. J. Climate, 22, 5597-5610.

Verdon, D. C., and S. W. Franks, 2005: Indian Ocean sea surface temperature variability and winter rainfall: Eastern Australia. Water Resour. Res., 41, W09413, doi:10.1029/2004WR003845.

Walker, G. T., 1923: Correlations in seasonal variations in weather, VIII. Mem. India Meteor. Dept., 24, 75-131.

Wang, G., and H. H. Hendon, 2007: Sensitivity of Australian rainfall to inter-El Niño variations. J. Climate, 20, 42114226.

Webster, P. J., A. M. Moore, J. P. Loschnigg, and R. R. Leben, 1999: Coupled ocean-atmosphere dynamics in the Indian Ocean during 1997-1998. Nature, 401, 356-360.

Wheeler, M. C., and H. H. Hendon, 2004: An all-season realtime multivariate MJO index: Development of an index for monitoring and prediction. Mon. Wea. Rev., 132, 1917- 1932.

S. Cleland, H. Meinke, and A. Donald, 2009: Impacts of the Madden-Julian oscillation on Australian rainfall and circulation. J. Climate, 22, 1482-1498.

Wilks, D. S., 2006: Statistical Methods in the Atmospheric Sciences. 2nd ed. International Geophysics Series, Vol. 59, Academic Press, 627 pp.

\section{AuthorAffiliation}

\section{ALEXANDRE O. FIERRO}

Cooperative Institute for Mesoscale Meteorological Studies, and NOAA/OAR/National Severe Storms Laboratory, University

of Oklahoma, Norman, Oklahoma, and Australian Sustainable Development Institute, Curtin University, Perth,

Australia

LANCE M. LESLIE

School of Meteorology, University of Oklahoma, Norman, Oklahoma, and Australian Sustainable Development Institute,

Curtin University, Perth, Australia

(Manuscript received 5 March 2012, in final form 17 September 2012)

Corresponding author address: Dr.Alexandre Fierro, Cooperative Institute for Mesoscale Meteorological Studies, National Weather Center, Suite 2100, 120 David L. Boren Blvd., Norman, OK 73072.

E-mail: afierro@ou.edu

\section{DETAILS}

Subject:

Meteorology; Precipitation; Colleges \&universities; Fishing industry; Trends; Principal components analysis 
Publication title:

Volume:

Issue:

Pages:

2222-2246

Number of pages:

25

Publication year:

2013

Publication date:

Apr 1, 2013

Publisher:

American Meteorological Society

Place of publication: Boston

Country of publication: United States

Publication subject: Meteorology

ISSN:

08948755

Source type:

Scholarly Journals

Language of publication: English

Document type: $\quad$ Feature

Document feature: $\quad$ Maps Tables Graphs References

ProQuest document ID: $\quad 1350277719$

Document URL:

http://ezproxy.lib.uts.edu.au/login?url=https://search.proquest.com/docview/13502 77719 ?accountid $=17095$

Copyright:

Copyright American Meteorological Society Apr 1, 2013

Last updated:

2017-02-04

Database:

Water Resources Abstracts,Meteorological \&Geoastrophysical

Abstracts,Environmental Sciences and Pollution Management,SciTech Premium Collection,Aqualine,ASFA: Aquatic Sciences and Fisheries Abstracts,ProQuest Central

\section{LINKS}


Copyright @ 2017 ProQuest LLC. All rights reserved.

Terms and Conditions Contact ProQuest 